\title{
Influence of fungicide application on limitation of fungi on oilseed rape siliques and seeds
}

\author{
Wpływ ochrony przy użyciu fungicydów na ograniczanie \\ występowania grzybów na łuszczynach i nasionach rzepaku
}

\author{
Ewa Jajor ${ }^{1}$, Joanna Horoszkiewicz-Janka ${ }^{1}$, Grzegorz Wickiel ${ }^{2}$
}

\begin{abstract}
Summary
The aim of the study was to assess the influence of fungicidal protection on limitation of rape siliques and seeds infection by fungi. The controlled experiments were conducted on rape winter and spring rape cultivars at the Field Experimental Station of the Institute of Plant Protection - National Research Institute in Winna Góra for three years. Fungicide treatments were carried out at the budding stage of rape and at the end of rape flowering. Percentage of silique surface infected was determined during ripening. After harvesting, yield parameters, seed colonization by fungi and mycotoxin content were assessed. In the conducted experiments, symptoms of Alternaria blight on siliques were mainly observed. Higher degree of silique infection and seed colonization by fungi from the genus Alternaria was noted in spring rape. Effectiveness of reduction of Alternaria blight infection by fungicides depended on analyzed season, cultivar and time of use of plant protection products. Oilseed rape yield of both cultivars was significantly and negatively correlated with infected rate of siliques. Seed colonization by fungi of the genus Alternaria was the highest in control and it was confirmed mainly in cultivar Licosmos. The conducted chromatographic analyses enabled to find small amounts of alternariol monomethyl ether and alternariol in rape seeds.
\end{abstract}

Key words: Alternaria blight, oilseed rape, treatment, siliques, seeds, mycotoxin

\section{Streszczenie}

Celem badań była ocena wpływu ochrony fungicydowej na ograniczanie występowania grzybów na łuszczynach i nasionach rzepaku. Doświadczenia ścisłe prowadzono w Winnej Górze, na terenie Polowej Stacji Doświadczalnej Instytutu Ochrony Roślin Państwowego Instytutu Badawczego, przez okres trzech lat, na odmianach rzepaku ozimego i jarego. Zabiegi przy użyciu fungicydów wykonywano w fazie pąkowania rzepaku oraz pod koniec kwitnienia roślin. W okresie dojrzewania określano procent porażonej powierzchni łuszczyn przez grzyby. Po zbiorze określano parametry plonu, zasiedlenie nasion oraz zawartość mikotoksyn. Na ocenianych łuszczynach występowały głównie objawy czerni krzyżowych. Większy poziom porażenia łuszczyn i zasiedlenie nasion przez grzyby rodzaju Alternaria notowano na formie jarej rzepaku. Skuteczność ograniczania występowania czerni krzyżowych przez fungicydy zależała od sezonu badań, odmiany i terminu użycia środków. Plon nasion rzepaku obu odmian był istotnie ujemnie skorelowany z poziomem porażenia łuszczyn. Zasiedlenie nasion przez grzyby rodzaju Alternaria było najwyższe w obiektach kontrolnych, co zostało to potwierdzone głównie na odmianie Licosmos. Przeprowadzona analiza chromatograficzna pozwoliła na stwierdzenie w nasionach rzepaku nieznacznej ilości eteru monometylowego alternariolu i alternariolu.

Słowa kluczowe: czerń krzyżowych, rzepak, ochrona, łuszczyny, nasiona, mikotoksyny

\footnotetext{
$\overline{1}$ Instytut Ochrony Roślin - Państwowy Instytut Badawczy Zakład Mikologii

Władysława Węgorka 20, 60-318 Poznań

e.jajor@iorpib.poznan.pl

${ }^{2}$ Laboratorium Badawcze SORBO Sp. z o.o.

Naramowicka 194, 61-611 Poznań
} 


\section{Wstęp / Introduction}

Grzyby rodzaju Leptosphaeria, anomorfa Phoma lingam (sucha zgnilizna kapustnych), rodzaju Alternaria (czerń krzyżowych), Sclerotinia sclerotiorum (zgnilizna twardzikowa) i Botryotinia fuckeliana, anamorfa Botrytis cinerea (szara pleśń), zalicza się do ważnych patogenów występujących na rzepaku w okresie wegetacji (Rimmer i wsp. 2007; Kryczyński i Weber 2011). Powodują one niejednokrotnie znaczne straty w ilości i jakości plonu nasion. Szkodliwość tych chorób, szczególnie czerni krzyżowych, jest potęgowana również przez fakt, że mogą one wystapić na łuszczynach. Silne porażenie łuszczyn prowadzi niekiedy do ich zamierania jeszcze przed zawiązaniem nasion. Najczęściej jednak porażenie powoduje przedwczesne zasychanie, pękanie i osypywanie się nasion. Nasiona $\mathrm{z}$ zainfekowanych łuszczyn są niedojrzałe, drobniejsze i pomarszczone. Charakteryzują się też niekiedy inną niż oczekiwana zawartością białek i tłuszczu (Conn i wsp. 1990; Rotem 1998). Nasiona te często zasiedlone są przez grzyby, co pogarsza ich zdolność kiełkowania, jeśli zostaną przeznaczone na materiał siewny (Korbas i wsp. 2011). Grzyby zasiedlające nasiona, między innymi rodzaju Alternaria, mają zdolność do wytwarzania toksycznych metabolitów (Tys i wsp. 2011). Do mikotoksyn występujących w nasionach rzepaku należą produkowane przez Alternaria alternata alternariol (AOH - alternariol) i eter monometylowy alternariolu (AME - alternariol monomethyl ether) (Gwiazdowski i Wickiel 2011; Jajor i wsp. 2011).

Zdrowotność roślin zależy od wielu czynników zarówno agrotechnicznych, jak i pogodowych, a także zastosowanych $\mathrm{w}$ odpowiednim terminie fungicydów. Wymiernym rezultatem współdziałania tych czynników staje się wysoki i dobrej jakości plon nasion.

Celem badań była ocena wpływu ochrony z użyciem fungicydów na ograniczenie występowania grzybów na łuszczynach i nasionach rzepaku, a także na wysokość plonu i zawartość mikotoksyn w nasionach.

\section{Materiały i metody / Materials and methods}

Doświadczenia prowadzono na terenie Polowej Stacji Doświadczalnej Instytutu Ochrony Roślin - Państwowego Instytutu Badawczego (PSD IOR - PIB) w Winnej Górze przez okres trzech sezonów wegetacyjnych. W latach 2005/2006-2007/2008 wysiewano rzepak ozimy odmiany Kaszub, a w latach 2007-2009 rzepak jary odmiany Licosmos. Dwuczynnikowe doświadczenia założono na poletkach o wymiarach $16,5 \mathrm{~m}^{2}$, w układzie bloków losowanych, w 4 powtórzeniach. W dwóch terminach (czynnik A), tj. w fazie pakkowania (BBCH 58-59) oraz pod koniec kwitnienia roślin (BBCH 68-69) wykonano zabieg przy użyciu dwóch fungicydów (czynnik B): Amistar 250 SC (azoksystrobina 250 g/l) i Caramba 60 SL (metkonazol 60 g/l). Na obiekcie kontrolnym nie stosowano fungicydu. Jednorazowo przed zbiorem na 100 losowo wybranych łuszczynach z każdego powtórzenia oceniano procent powierzchni $\mathrm{z}$ objawami chorób. W czasie zbioru określano wysokość plonu z poletek.
W celu oceny zasiedlenia nasion przez grzyby, materiał uzyskany z poszczególnych poletek odkażano przez $4 \mathrm{mi}-$ nuty w $5 \%$ podchlorynie sodu, trzykrotnie płukano w wodzie destylowanej i suszono na sterylnej bibule, a następnie wykładano po 100 nasion w 4 powtórzeniach na płytki Petriego z zakwaszoną pożywką PDA (Potato Dextrose Agar). Po 7-dniowej inkubacji w temperaturze $18^{\circ} \mathrm{C}$, przy fotoperiodzie $12 / 12 \mathrm{~h}$ oceniano procent ogólnej liczby nasion zasiedlonych przez grzyby, a po 2-3 tygodniach identyfikowano gatunki grzybów (Mathur i Kongsdal 2003; Simmons 2007).

Określenie zawartości alternariolu $(\mathrm{AOH})$ i eteru monometylowego alternariolu (AME) w nasionach rzepaku z poszczególnych obiektów wykonano w Zakładzie Badania Środków Ochrony Roślin IOR - PIB według metody opracowanej przez Wickiela i wsp. (2010). AOH i AME ekstrahowano z próbki nasion rzepaku mieszaniną metanolu i wody. Przefiltrowany ekstrakt oczyszczano na polimerycznych kolumienkach do ekstrakcji do fazy stałej - Oasis HLB firmy Waters. Toksyny eluowano mieszaniną metanolu i acetonitrylu. Eluat odparowywano, a pozostałość rozpuszczano w fazie ruchomej do analizy chromatograficznej. Wymienione mikotoksyny oznaczano z zastosowaniem wysokosprawnej chromatografii cieczowej w układzie faz odwróconych (HPLC-RP - high performance liquid chromatography-refersed-phase) $\mathrm{z}$ detekcją fluorometryczną (FLD - fluorometric detection).

Uzyskane w doświadczeniach wyniki poddano dwuczynnikowej analizie statystycznej $\mathrm{z}$ zastosowaniem analizy wariancji. Istotność różnic oceniano testem t-Studenta na poziomie $p=0,05$. Obliczono także współczynniki korelacji między procentem powierzchni łuszczyn porażonej przez grzyby rodzaju Alternaria a plonem nasion.

\section{Wyniki i dyskusja / Results and discussion}

Na łuszczynach w ocenianych doświadczeniach występowały głównie objawy czerni krzyżowych oraz w dużo mniejszym nasileniu symptomy szarej pleśni.

Występowanie czerni krzyżowych na obu odmianach oraz zasiedlenie nasion przez grzyby rodzaju Alternaria zależało od zastosowanej ochrony i było często mniejsze po zabiegu wykonanym pod koniec kwitnienia (w fazie BBCH 68-69) (tab. 1, 2). Zostało to potwierdzone statystycznie tylko w trzecim roku badań (2009), kiedy wystapiła wyjątkowo silna presja infekcyjna. Zanotowano wówczas istotnie mniej zasiedlonych nasion rzepaku jarego po zabiegu w drugim terminie $(59,67 \%)$ w porównaniu do obiektów, w których fungicydy zastosowano w pierwszym terminie $(66,83 \%)$ (tab. 2). W innych badaniach, termin przeprowadzenia zabiegu nie wpływał istotnie na analizowane $\mathrm{w}$ doświadczeniu parametry, co mogło wynikać z niskiego poziomu porażenia roślin. Jednakże średnia z 4 lat badań wykazuje tendencję niższego porażenia łuszczyn w przypadku opóźnienia terminu zabiegu, co pozwala sugerować, że zbyt wczesne wykonywanie zabiegów nie daje gwarancji skutecznej ochrony łuszczyn (Jajor i wsp. 2008). Podobnie Brazauskiene i Petraitiene $(2002,2003)$ w swoich badanich prze- 
Tabela 1. Wpływ ochrony przy użyciu fungicydów na ograniczanie występowania czerni krzyżowych na łuszczynach Table 1. Influence of fungicidal protection on limitation of Alternaria blight on siliques

\begin{tabular}{|c|c|c|c|c|c|}
\hline \multirow{2}{*}{\multicolumn{2}{|c|}{$\begin{array}{l}\text { Odmiana/czynnik } \\
\text { Cultivar/factor }\end{array}$}} & \multicolumn{3}{|c|}{$\begin{array}{l}\text { Sezon badań/procent porażonej powierzchni } \\
\text { Season of experiments/percent of area infected }\end{array}$} & \multirow{2}{*}{$\begin{array}{c}\text { Średnio z lat } \\
\text { Mean for the years }\end{array}$} \\
\hline & & I & II & III & \\
\hline \multicolumn{6}{|c|}{ Kaszub } \\
\hline \multirow{2}{*}{$\begin{array}{l}\text { A. Termin zabiegu } \\
\text { Date of treatment }\end{array}$} & BBCH 58-59 & 3,02 & 5,62 & 1,82 & 3,48 \\
\hline & BBCH 68-69 & 2,71 & 6,22 & 1,23 & 3,38 \\
\hline \multicolumn{2}{|c|}{$\operatorname{NIR}(0,05)-\operatorname{LSD}(0.05)$} & r.n. & r.n. & r.n. & r.n. \\
\hline \multirow{3}{*}{$\begin{array}{l}\text { B. Fungicyd } \\
\text { Fungicide }\end{array}$} & Amistar $250 \mathrm{SC}$ & 1,08 & 4,12 & 0,62 & 1,94 \\
\hline & Caramba $60 \mathrm{SL}$ & 1,06 & 3,71 & 0,50 & 1,75 \\
\hline & kontrola - untreated & 6,46 & 9,94 & 3,47 & 6,62 \\
\hline \multicolumn{2}{|c|}{ NIR $(0,05)-\operatorname{LSD}(0.05)$} & 3,149 & 1,629 & 0,842 & 2,160 \\
\hline \multicolumn{6}{|c|}{ Licosmos } \\
\hline \multirow{2}{*}{$\begin{array}{l}\text { A. Termin zabiegu } \\
\text { Date of treatment }\end{array}$} & BBCH 58-59 & 9,56 & 5,79 & 16,22 & 10,52 \\
\hline & ВBCH 68-69 & 10,44 & 5,71 & 9,57 & 8,57 \\
\hline \multicolumn{2}{|c|}{$\operatorname{NIR}(0,05)-\operatorname{LSD}(0.05)$} & r.n. & r.n. & r.n. & r.n. \\
\hline \multirow{3}{*}{$\begin{array}{l}\text { B. Fungicyd } \\
\text { Fungicide }\end{array}$} & Amistar $250 \mathrm{SC}$ & 6,16 & 5,50 & 13,29 & 8,32 \\
\hline & Caramba $60 \mathrm{SL}$ & 6,41 & 3,32 & 7,58 & 5,77 \\
\hline & kontrola - untreated & 17,42 & 8,43 & 17,81 & 14,55 \\
\hline \multicolumn{2}{|c|}{$\operatorname{NIR}(0,05)-\operatorname{LSD}(0.05)$} & 3,651 & 1,436 & 6,866 & 5,763 \\
\hline
\end{tabular}

r.n. - różnica nieistotna - not significant difference

Tabela 2. Wpływ ochrony przy użyciu fungicydów na ograniczanie zasiedlenia nasion przez grzyby rodzaju Alternaria Table 2. Influence of fungicidal protection on limitation seed colonization by fungi of the genus Alternaria

\begin{tabular}{|c|c|c|c|c|c|}
\hline \multirow{2}{*}{\multicolumn{2}{|c|}{$\begin{array}{l}\text { Odmiana/czynnik } \\
\text { Cultivar/factor }\end{array}$}} & \multicolumn{3}{|c|}{$\begin{array}{c}\text { Sezon badań/procent nasion porażonych } \\
\text { Season of experiments/percent of seed infected }\end{array}$} & \multirow{2}{*}{$\begin{array}{c}\text { Średnio } \mathrm{z} \text { lat } \\
\text { Mean for the years }\end{array}$} \\
\hline & & I & II & III & \\
\hline \multicolumn{6}{|c|}{ Kaszub } \\
\hline \multirow{2}{*}{$\begin{array}{l}\text { A. Termin zabiegu } \\
\text { Date of treatment }\end{array}$} & BBCH 58-59 & 4,41 & 11,00 & 3,91 & 6,44 \\
\hline & BBCH $68-69$ & 4,41 & 13,00 & 2,75 & 6,72 \\
\hline \multicolumn{2}{|c|}{$\operatorname{NIR}(0,05)-\operatorname{LSD}(0.05)$} & r.n. & r.n. & r.n. & r.n. \\
\hline \multirow{3}{*}{$\begin{array}{l}\text { B. Fungicyd } \\
\text { Fungicide }\end{array}$} & Amistar $250 \mathrm{SC}$ & 3,63 & 9,50 & 2,88 & 5,33 \\
\hline & Caramba $60 \mathrm{SL}$ & 4,38 & 13,00 & 2,00 & 6,46 \\
\hline & kontrola - untreated & 5,25 & 13,50 & 5,12 & 7,96 \\
\hline \multicolumn{2}{|c|}{$\operatorname{NIR}(0,05)-\operatorname{LSD}(0.05)$} & r.n. & r.n. & r.n. & 1,923 \\
\hline \multicolumn{6}{|c|}{ Licosmos } \\
\hline \multirow{2}{*}{$\begin{array}{l}\text { A. Termin zabiegu } \\
\text { Date of treatment }\end{array}$} & BBCH 58-59 & 39,33 & 30,58 & 66,83 & 45,58 \\
\hline & ВBCH 68-69 & 40,08 & 22,92 & 59,67 & 40,89 \\
\hline \multicolumn{2}{|c|}{$\operatorname{NIR}(0,05)-\operatorname{LSD}(0.05)$} & r.n. & r.n. & 0,919 & r.n. \\
\hline \multirow{3}{*}{$\begin{array}{l}\text { B. Fungicyd } \\
\text { Fungicide }\end{array}$} & Amistar $250 \mathrm{SC}$ & 31,63 & 21,63 & 69,00 & 40,75 \\
\hline & Caramba $60 \mathrm{SL}$ & 42,63 & 24,00 & 59,00 & 41,88 \\
\hline & kontrola - untreated & 44,88 & 34,62 & 61,75 & 47,08 \\
\hline \multicolumn{2}{|c|}{$\operatorname{NIR}(0,05)-\operatorname{LSD}(0.05)$} & 8,423 & 9,771 & 2,070 & r.n. \\
\hline
\end{tabular}

r.n. - różnica nieistotna - not significant difference 
Tabela 3. Wpływ ochrony przy użyciu fungicydów na plon nasion badanych odmian rzepaku [t/ha]

Table 3. Influence of fungicidal protection on seed yield of the examined rape cultivars $[\mathrm{t} / \mathrm{ha}]$

\begin{tabular}{|c|c|c|c|c|c|}
\hline \multirow{2}{*}{\multicolumn{2}{|c|}{$\begin{array}{c}\text { Odmiana/czynnik } \\
\text { Cultivar/factor }\end{array}$}} & \multicolumn{3}{|c|}{$\begin{array}{c}\text { Sezon badań/plon } \\
\text { Season of experiments/yield }\end{array}$} & \multirow{2}{*}{$\begin{array}{c}\text { Średnio } \mathrm{z} \text { lat } \\
\text { Mean for the years }\end{array}$} \\
\hline & & I & II & III & \\
\hline \multicolumn{6}{|c|}{ Kaszub } \\
\hline \multirow{2}{*}{$\begin{array}{l}\text { A. Termin } \\
\text { zabiegu } \\
\text { Date of } \\
\text { treatment }\end{array}$} & BBCH 58-59 & 4,45 & 4,11 & 4,09 & 4,21 \\
\hline & ВBCH 68-69 & 4,51 & 4,10 & 4,09 & 4,23 \\
\hline \multicolumn{2}{|c|}{$\operatorname{NIR}(0,05)-\operatorname{LSD}(0.05)$} & r.n. & r.n. & r.n. & r.n. \\
\hline \multirow{3}{*}{$\begin{array}{l}\text { B. Fungicyd } \\
\text { Fungicide }\end{array}$} & Amistar $250 \mathrm{SC}$ & 4,68 & 3,99 & 4,36 & 4,34 \\
\hline & Caramba $60 \mathrm{SL}$ & 4,74 & 4,31 & 4,35 & 4,47 \\
\hline & kontrola - untreated & 4,03 & 4,01 & 3,56 & 3,87 \\
\hline \multicolumn{2}{|c|}{$\operatorname{NIR}(0,05)-\operatorname{LSD}(0.05)$} & 0,193 & 0,252 & 0,350 & 0,501 \\
\hline \multicolumn{6}{|c|}{ Licosmos } \\
\hline \multirow{2}{*}{$\begin{array}{l}\text { A. Termin } \\
\text { zabiegu } \\
\text { Date of } \\
\text { treatment }\end{array}$} & BBCH 58-59 & 1,61 & 1,73 & 0,45 & 1,26 \\
\hline & ВBCH 68-69 & 1,64 & 1,62 & 0,46 & 1,23 \\
\hline \multicolumn{2}{|c|}{$\operatorname{NIR}(0,05)-\operatorname{LSD}(0.05)$} & r.n. & r.n. & r.n. & r.n. \\
\hline \multirow{3}{*}{$\begin{array}{l}\text { B. Fungicyd } \\
\text { Fungicide }\end{array}$} & Amistar $250 \mathrm{SC}$ & 1,58 & 1,50 & 0,53 & 1,20 \\
\hline & Caramba $60 \mathrm{SL}$ & 1,86 & 1,94 & 0,56 & 1,45 \\
\hline & kontrola - untreated & 1,44 & 1,58 & 0,28 & 1,10 \\
\hline \multicolumn{2}{|c|}{$\operatorname{NIR}(0,05)-\operatorname{LSD}(0.05)$} & r.n. & r.n. & 0,095 & 0,259 \\
\hline
\end{tabular}

r.n. - różnica nieistotna - not significant difference

Tabela 4. Współczynniki korelacji pomiędzy plonem nasion badanych odmian a porażeniem łuszczyn rzepaku przez czerń krzyżowych

Table 4. Correlation coefficients between seed yield of the examined cultivars and rape siliques infected by Alternaria blight

\begin{tabular}{c|c|c}
\hline $\begin{array}{c}\text { Sezon badań } \\
\text { Season of experiments }\end{array}$ & $\begin{array}{c}\text { Odmiana } \\
\text { Cultivar }\end{array}$ & $\begin{array}{c}\text { Wartość współczynnika korelacji } \\
\text { Correlation coefficients }\end{array}$ \\
\hline \multirow{2}{*}{ I } & Kaszub & $-0,666^{* *}$ \\
\cline { 2 - 3 } & Licosmos & $-0,233$ \\
\hline \multirow{2}{*}{ II } & Kaszub & $-0,483^{* *}$ \\
\cline { 2 - 3 } & Licosmos & $-0,370^{*}$ \\
\hline \multirow{2}{*}{ III } & Kaszub & $-0,595^{* *}$ \\
\cline { 2 - 3 } & Licosmos & $-0,538^{* *}$ \\
\hline
\end{tabular}

*współczynniki korelacji istotne przy $\mathrm{p}<0,05$ - correlation coefficients significant at $\mathrm{p}<0.05$

**współczynniki korelacji istotne przy $\mathrm{p}<0,01-$ correlation coefficients significant at $\mathrm{p}<0.01$

Tabela 5. Zawartość mikotoksyn alternaryjnych w nasionach badanych odmian

Table 5. The content of Alternaria mycotoxin in oilseed rape cultivars

\begin{tabular}{|c|c|c|c|c|c|c|c|}
\hline \multirow{3}{*}{$\begin{array}{l}\text { Termin zabiegu } \\
\text { Date of treatment }\end{array}$} & \multirow{3}{*}{$\begin{array}{l}\text { Fungicyd } \\
\text { Fungicide }\end{array}$} & \multicolumn{6}{|c|}{$\begin{array}{l}\text { Sezon badań/mikotoksyny } \\
\text { Season of experiments/mycotoxin } \\
{[\mathrm{ng} / \mathrm{g}]}\end{array}$} \\
\hline & & \multicolumn{2}{|c|}{$\mathrm{I}$} & \multicolumn{2}{|c|}{ II } & \multicolumn{2}{|c|}{ III } \\
\hline & & $\mathrm{AOH}$ & AME & $\mathrm{AOH}$ & AME & $\mathrm{AOH}$ & AME \\
\hline 1 & 2 & 3 & 4 & 5 & 6 & 7 & 8 \\
\hline \multicolumn{8}{|c|}{ Kaszub } \\
\hline \multirow{3}{*}{ ВBCH 58-59 } & Amistar $250 \mathrm{SC}$ & $<$ LOD & 6,4 & $<\mathrm{LOQ}$ & 10,5 & $<$ LOD & $<\mathrm{LOD}$ \\
\hline & Caramba $60 \mathrm{SL}$ & $<$ LOD & 6,2 & $<$ LOD & $<$ LOQ & $<$ LOD & $<\mathrm{LOD}$ \\
\hline & kontrola - untreated & $<$ LOD & 6,3 & $<$ LOD & 4,2 & $<$ LOD & 12,4 \\
\hline
\end{tabular}




\begin{tabular}{|c|c|c|c|c|c|c|c|}
\hline 1 & 2 & 3 & 4 & 5 & 6 & 7 & 8 \\
\hline \multirow{3}{*}{ ВBCH 68-69 } & Amistar $250 \mathrm{SC}$ & $<$ LOD & 5,8 & $<$ LOD & $<\mathrm{LOQ}$ & $<\mathrm{LOD}$ & $<\mathrm{LOD}$ \\
\hline & Caramba $60 \mathrm{SL}$ & $<$ LOD & 5,6 & $<$ LOD & 11,7 & $<$ LOD & $<$ LOD \\
\hline & kontrola - untreated & $<$ LOD & 7,8 & $<$ LOQ & 5,9 & $<\mathrm{LOD}$ & $<\mathrm{LOD}$ \\
\hline \multicolumn{8}{|c|}{ Licosmos } \\
\hline \multirow{3}{*}{ ВBCH 58-59 } & Amistar $250 \mathrm{SC}$ & $<$ LOD & 9,2 & $<\mathrm{LOQ}$ & $<\mathrm{LOD}$ & $<$ LOD & 9,4 \\
\hline & Caramba $60 \mathrm{SL}$ & $<$ LOQ & $<$ LOD & $<$ LOQ & $<\mathrm{LOD}$ & $<\mathrm{LOD}$ & $<$ LOQ \\
\hline & kontrola - untreated & $<$ LOQ & $<$ LOD & $<\mathrm{LOQ}$ & $<\mathrm{LOD}$ & $<\mathrm{LOD}$ & $<\mathrm{LOD}$ \\
\hline \multirow{3}{*}{ ВВСН 68-69 } & Amistar $250 \mathrm{SC}$ & $<$ LOD & $<$ LOD & $<$ LOD & $<\mathrm{LOD}$ & $<$ LOD & 4,7 \\
\hline & Caramba $60 \mathrm{SL}$ & $<$ LOD & $<$ LOD & $<$ LOD & $<$ LOD & $<\mathrm{LOD}$ & $<$ LOQ \\
\hline & kontrola - untreated & $<$ LOQ & $<$ LOD & $<$ LOQ & $<\mathrm{LOD}$ & $<\mathrm{LOD}$ & 4,4 \\
\hline
\end{tabular}

$\mathrm{AOH}$ - alternariol, AME - alternariol monomethyl ether

LOD - granica wykrywalności - limit of detection $\mathrm{AOH}=0,8[\mathrm{ng} / \mathrm{g}], \mathrm{AME}=1,2[\mathrm{ng} / \mathrm{g}]$

LOQ - granica oznaczalności - limit of quantitation $\mathrm{AOH}=2,0[\mathrm{ng} / \mathrm{g}], \mathrm{AME}=4,0[\mathrm{ng} / \mathrm{g}]$

prowadzonych w latach 1997-2001 uzyskały wysoką skuteczność fungicydów zastosowanych pod koniec fazy kwitnienia rzepaku jarego i ozimego lub gdy ukazały się pierwsze zmiany chorobowe na łuszczynach. Mączyńska i wsp. (2001) nie stwierdzili w sezonie o niskim porażeniu liści i łuszczyn przez Alternaria spp. wpływu terminów stosowania fungicydów na zdrowotność łuszczyn, natomiast $\mathrm{w}$ warunkach silnej presji choroby optymalnym terminem zwalczania czerni krzyżowych był początek kwitnienia.

W obiektach kontrolnych występowanie czerni krzyżowych okazało się istotnie największe na obu odmianach rzepaku (tab. 1). Średnio z lat w obiektach kontrolnych procent porażonych łuszczyn odmiany Kaszub wynosił 6,62 , a odmiany Licosmos 14,55, podczas gdy w przypad$\mathrm{ku}$ zastosowania fungicydów wynosił on odpowiednio od 1,75 do 1,94 oraz 5,77 do 8,32. Fungicyd Caramba 60 SL często lepiej ograniczał porażenie łuszczyn przez Alternaria spp. niż Amistar 250 SC. Znalazło to potwierdzenie statystyczne w drugim sezonie badań (2008) na odmianie Licosmos $(3,32 \%$ - Caramba 60 SL i 5,50\% - Amistar 250 SC). Mączyńska i wsp. (2002) również podkreślają wysoką skuteczność metkonazolu (Caramba 60 SL), który w warunkach późnej i silnej infekcji łuszczyn wpływał istotnie na ograniczenie nasilenia chorób na łuszczynach.

Zasiedlenie nasion przez grzyby rodzaju Alternaria (A. alternata, A. brassicae, A. brassicicola) było wyższe w obiektach kontrolnych, ale w stopniu istotnym statystycznie jedynie na odmianie Licosmos (tab. 2). Zdecydowanie najmniejsze zasiedlenie nasion przez Alternaria spp. w kombinacjach chronionych przy użyciu fungicydów stwierdzili również Gwiazdowski i Wickiel (2011). W badaniach własnych zaobserwowano zróżnicowaną skuteczność poszczególnych fungicydów. Analizując jednak średnią wartość z lat w przypadku obu odmian, mniej zasiedlonych nasion zaobserwowano po zastosowaniu fungicydu Amistar 250 SC. Przy czym jedynie u odmiany Kaszub istotnie najmniej zasiedlonych nasion zaobserwowano w obiektach potraktowanych tym fungicydem (średnio 5,33\%).

$\mathrm{Na}$ wielkość plonu nasion (tab. 3), niezależnie od terminu wykonania zabiegu, istotny wpływ miała ochrona przy użyciu fungicydów. Najwyższy plon uzyskano po zastosowaniu fungicydu Caramba $60 \mathrm{SL}$. W przypadku odmiany Licosmos średni plon nasion $\mathrm{z}$ lat wynosił $1,45 \mathrm{t} /$ ha $\mathrm{i}$ był istotnie wyższy od pozostałych obiektów. Wpływ metkonazolu na wzrost plonu nasion podkreślały też Mączyńska i wsp. (2002). Plon nasion rzepaku obu odmian był istotnie ujemnie skorelowany $\mathrm{z}$ poziomem porażenia łuszczyn (tab. 4). Świadczy to o silnym wpływie porażenia łuszczyn rzepaku przez czerń krzyżowych na redukcję plonu nasion. Znajduje to również potwierdzenie w innych badaniach (Jajor i wsp. 2008).

$\mathrm{Z}$ uwagi na liczne występowanie na nasionach gatunku A. alternata przeprowadzono analizę mikotoksyn (tab. 5). Gatunek ten ma zdolność produkowania wielu mikotoksyn, co może wpływać negatywnie na jakość produktów pozyskiwanych z nasion rzepaku (Sadowski i wsp. 2005). Analiza chromatograficzna wykazała w nasionach rzepaku nieznaczne ilości eteru monometylowego alternariolu i alternariolu. Niska zawartość tych związków nie pozwoliła na wyróżnienie czynnika, który byłby w tym przypadku decydujący. W badaniach Gwiazdowskiego i Wickiela (2009) zawartość mikotoksyn w nasionach jarych odmian rzepaku była wyższa niż w ozimych, co było związane z większym zasiedleniem tych nasion przez grzyby rodzaju Alternaria. W badaniach własnych, w rzepaku jarym odmiany Licosmos występowanie tego gatunku na nasionach było również wyższe niż w przypadku ozimej odmiany Kaszub, jednak w większości nie stwierdzono w nich mikotoksyn. Potwierdza to wnioski innych badań, że duże zasiedlenie nasion przez grzyby nie zawsze wpływa na wysoką ilość wytwarzanych przez nie mikotoksyn i odwrotnie (Horoszkiewicz-Janka i wsp. 2010; Gwiazdowski i Wickiel 2011).

\section{Wnioski / Conclusions}

1. Zastosowanie fungicydów pod koniec kwitnienia wpływa $\mathrm{w}$ największym stopniu na ograniczenie występowania czerni krzyżowych na łuszczynach i zasiedlenie nasion przez grzyby rodzaju Alternaria. 
2. Skuteczność ochrony łuszczyn i plon nasion rzepaku zależy zarówno od terminu wykonania zabiegu, jak i zastosowanego fungicydu.

3. Silne porażenie łuszczyn przez grzyby rodzaju Alternaria wpływa na redukcję plonu nasion.
4. Grzyby rodzaju Alternaria zasiedlające nasiona rzepaku wykazują małą zdolność produkowania mikotoksyn - eteru monometylowego alternariolu i alternariolu.

\section{Literatura / References}

Brazauskiene I., Petraitiene E. 2002. Dark leaf and pod spot (Alternaria brassicae) on oilseed (Brassica napus) in Lithuania. Plant Prot. Sci. 38: 384-387.

Brazauskiene I., Petraitiene E. 2003. Dynamic of Alternaria blight (Alternaria spp.) spread on spring oilseed rape leaves and siliques and variation of the disease parameters under the effect of prochloraz and tebuconazole in relation application time. J. Plant Prot. Res. 43 (4): 313-323.

Conn K.L., Tewari J.P., Awasthi R.P. 1990. A disease assessment key for Alternaria black spot in rapeseed and mustard. Can. Plant Dis. Surv. 70: 19-22.

Gwiazdowski R., Wickiel G. 2009. Występowanie mikotoksyn alternaryjnych w nasionach rzepaku w zależności od odmian. [Occurrence of Alternaria mycotoxins in seeds of different rape cultivars]. Prog. Plant Prot./Post. Ochr. Roślin 49 (2): 934-937.

Gwiazdowski R., Wickiel G. 2011. Wpływ stosowania fungicydu na ograniczanie w nasionach rzepaku ozimego zawartości toksyn grzybów z rodzaju Alternaria. [The influence of fungicide protection on the decrease of Alternaria toxins amount in the seeds of winter oilseed rape]. Prog. Plant Prot./Post. Ochr. Roślin 51 (3): 1409-1414.

Horoszkiewicz-Janka J., Korbas M., Jajor E., Krawczyk R. 2010. Mycotoxins content and colonization level in winter wheat grain cultivated in transition period following to ecological system. J. Res. Appl. Agric. Engin. 55 (3): 117-121.

Jajor E., Wickiel G., Horoszkiewicz-Janka J. 2011. Grzyby rodzaju Alternaria i ich toksyczne metabolity występujące na nasionach rzepaku ozimego. [Fungi of the Alternaria genus and their toxic metabolites in seeds of winter oilseed rape]. Prog. Plant Prot./Post. Ochr. Roślin 51 (4): 1634-1638.

Jajor E., Wójtowicz M., Pieczul K. 2008. Wpływ warunków hydrotermicznych i terminu ochrony fungicydowej na występowanie grzybów z rodzaju Alternaria na rzepaku. [Influence of weather conditions and date of fungicidal control on occurrence of Alternaria spp. on oilseed rape]. Prog. Plant Prot./Post. Ochr. Roślin 48 (3): 1048-1054.

Korbas M., Jajor E., Danielewicz J., Wickiel G. 2011. Fungi of oilseed rape seeds - occurrence and importance. p. 141-154. In: "Advances in Analysis and Technology of Rapeseed Oil" (E. Szłyk, ed.). Monograph. Wyd. Nauk. UMK, Toruń, 218 pp.

Kryczyński S., Weber Z. 2011 (red.). Fitopatologia. T. 2. Choroby roślin uprawnych. PWRiL, Poznań, 464 ss.

Mathur S.B., Kongsdal O. 2003. Common Laboratory Seed Health Testing Methods for Detecting Fungi. Int. Seed Testing Association, CH-Switzerland, $425 \mathrm{pp}$.

Mączyńska A., Krzyzińska B., Drzewiecki S. 2001. Wpływ różnych terminów stosowania fungicydów na zdrowotność łuszczyn rzepaku ozimego. [Influence of different terms of application on fungicides on health of winter rape pods]. Prog. Plant Prot./Post. Ochr. Roślin 41 (2): 638-642.

Mączyńska A., Krzyzińska B., Pietryga J. 2002. Efektywność zwalczania chorób łuszczyn rzepaku ozimego przy wczesnej i późnej infekcji. Rośliny Oleiste - Oilseed Crops 23 (1): 409-416.

Rimmer S.R., Shattuck V.I., Buchwaldt I. 2007. Compendium of Brassica Diseases. APS Press, St. Paul, MN, 117 pp.

Rotem J. 1998. The Genus Alternaria. Biology, Epidemiology and Pathogenicity. APS Press, St. Paul, MN, 326 pp.

Sadowski Cz., Lenc L., Pańka D. 2005. Wpływ stosowania siarki, magnezu, boru i fungicydów na zdrowotność i zasiedlenie przez grzyby nasion rzepaku jarego „Margo”. Rocz. AR Poznań 64: 143-153.

Simmons E.G. 2007. Alternaria. An Identification Manual. CBS Fungal Biodiversity Series No. 6, Utrecht, 775 pp.

Tys J., Rusinek R., Olejarski P., Korbas M., Jajor E., Gładkowski K. 2011. Teraz rzepak teraz olej. T. V. Suszenie i przechowywanie nasion rzepaku. Wyd. PSPO, Warszawa, 104 ss.

Wickiel G., Wower K., Gwiazdowski R., Horoszkiewicz-Janka J., Jajor E., Korbas M. 2010. Determination of selected Alternaria mycotoxins in rapeseed, rapeseed meal and rapeseed cake. p. 47. 9th Int. Congres: Mycotoxins and Moulds. Bydgoszcz, 28-29.06.2010, 88 pp. 